\title{
Occurrence of bla virulence genes in avian ESBL-producing Escherichia coli isolates from Tunisia
}

\section{OPEN ACCESS}

Edited by:

Ghassan M. Matar

American University of Beirut,

Lebanon

Reviewed by:

Torsten Eckstein,

Colorado State University, USA

Paras Jain,

Albert Einstein College of Medicine of

Yeshiva University, New York, USA

*Correspondence:

Mohamed Salah Abbassi, Institute of Veterinary Research of Tunisia, 20 Street Jebel Lakhdhar, Bab

Saadoun, Tunis 1006, Tunisia salahtoumi_mohamed@yahoo.com

Received: 15 January 2015 Accepted: 13 April 2015 Published: 05 May 2015

Citation:

Kilani H, Abbassi MS, Ferjani S, Mansouri R, Sghaier S, Ben Salem R,

Jaouani I, Douja G, Brahim S, Hammami S, Ben Chehida N and Boubaker IB (2015) Occurrence of bla CTX-M-1, qnrB1 and virulence genes in avian ESBL-producing

Escherichia coli isolates from Tunisia. Front. Cell. Infect. Microbiol. 5:38. doi: 10.3389/fcimb.2015.00038

\begin{abstract}
Hajer Kilani ${ }^{1,2}$, Mohamed Salah Abbassi ${ }^{1,2 *}$, Sana Ferjani ${ }^{2,3}$, Riadh Mansouri ${ }^{1,4}$, Senda Sghaier ${ }^{1}$, Rakia Ben Salem ${ }^{1}$, Imen Jaouani ${ }^{1}$, Gtari Douja ${ }^{1}$, Sana Brahim ${ }^{1}$, Salah Hammami ${ }^{5}$, Noureddine Ben Chehida ${ }^{1}$ and Ilhem Boutiba-Ben Boubaker ${ }^{2,3}$

${ }^{1}$ Laboratory of Bacteriological Research, Institut de la Recherche Vétérinaire de Tunis, Université de Tunis El Manar, Tunis, Tunisia, ${ }^{2}$ LR99ESO9 Laboratoire de Résistance aux Antimicrobiens, Faculté de Médecine de Tunis, Université de Tunis El Manar, Tunis, Tunisia, ${ }^{3}$ Hôpital Charles Nicolle, Service de Microbiologie, Tunis, Tunisia, ${ }^{4}$ Regional Animal Health Center for North Africa (RAHC-NA), Tunis, Tunisia, ${ }^{5}$ École Nationale de Médecine Vétérinaire de Sidi Thabet, Sidi Thabet, Tunisia
\end{abstract}

Avian ESBL-producing Escherichia coli isolates have been increasingly reported worldwide. Animal to human dissemination, via food chain or direct contact, of these resistant bacteria has been reported. In Tunisia, little is known about avian ESBL- producing E. coli and further studies are needed. Seventeen ESBL-producing Escherichia coli isolates from poultry feces from two farms (Farm 1 and farm 2) in the North of Tunisia have been used in this study. Eleven of these isolates (from farm 1) have the same resistance profile to nalidixic acid, sulfonamides, streptomycin, tetracycline, and norfloxacine (intermediately resistant). Out of the six isolates recovered from farm 2, only one was co-resistant to tetracycline. All isolates, except one, harbored bla $\mathrm{CTX}_{\mathrm{M} M-1}$ gene, and one strain co-harbored the bla $\mathrm{TEM}_{\mathrm{T}-1}$ gene. The genes tet $A$ and tet $B$ were carried, respectively, by 11 and 1 amongst the 12 tetracycline-resistant isolates. Sulfonamides resistance was encoded by sul1, sul2, and sul3 genes in 3, 17, and 5 isolates, respectively. The qnrB1 was detected in nine strains, one of which co-harbored qnrS1 gene. The search for the class 1 and 2 integrons by PCR showed that in farm 1 , class 1 and 2 integrons were found in one and ten isolates, respectively. In farm 2, class 1 integron was found in only one isolate, class 2 was not detected. Only one gene cassette arrangement was demonstrated in the variable regions (VR) of the 10 int2-positive isolates: dfrA1- sat2-aadA1. The size of the VR of the class 1 integron was approximately $250 \mathrm{bp}$ in one int1-positive isolate, whereas in the second isolate, no amplification was observed. All isolates of farm 1 belong to the phylogroup A (sub-group A0). However, different types of phylogroups in farm 2 were detected. Each of the phylogroups $\mathrm{A} 1, \mathrm{~B} 22_{2}, \mathrm{~B} 23$ was detected in one strain, while the D2 phylogroup was found in 3 isolates. The virulence genes iutA, fimH, and traT were detected in 3, 7, and 3 isolates, respectively. Two types of gene combination were detected: iut $A+f i m H+t r a T$ in 3 isolates and iut $A+f i m H$ in one isolate. The isolates recovered in farm 1 showed the same profile of PFGE macro-restriction, while isolates of farm 2 presented unrelated PFGE patterns. We conclude that these avian ESBL-producing E. coli isolates show homo- and heterogenic genetic background and that plasmids harboring ESBL genes could be involved in the dissemination of this resistance phenotype.

Keywords: Escherichia coli, poultry, bla $\mathrm{CTX}-\mathrm{M}-1$, qnrB1, integrons, clonality 


\section{Introduction}

Escherichia coli is a commensal bacterium in humans and animals and considered an indicator of fecal contamination of food. Antimicrobial resistant isolates and resistance genes of $E$. coli can be transferred to humans through the food chain. This transfer represents a potential risk for public health (Alexander et al., 2010; Cortés et al., 2010; Canton et al., 2012; Ryu et al., 2012). The use of broad-spectrum cephalosporins in animals, such as ceftiofur and cefquinome, has been recognized a major driving force for the selection and spread of extended spectrum beta-lactamases (ESBL) (Dutil et al., 2010). In both reservoirs, high prevalence of genes belonging to CTX-M group dominates. Numerous data highlight the extent to which certain ESBL genes, ESBL plasmids or ESBL-producing clones are shared between animals and humans (Naseer and Sundsfjord, 2011).

In recent years, there has been increasing concern in the scientific community about the emergence and dissemination of E. coli strains producing ESBLs, especially of the CTX-M class, which are very frequently associated with community infections (Eckert et al., 2004; Livermore et al., 2007; Pitout and Laupland, 2008). Recently, different reports have indicated the dissemination of ESBL-positive E. coli strains among the intestinal microbiota of healthy humans (Vinué et al., 2009), in food producing animals, and in food products (Brinas et al., 2005; Blanc et al., 2006; Girlich et al., 2007; Jouini et al., 2007; Li et al., 2007; Smet et al., 2008). These resistant bacteria could be transferred to humans through the food chain. This transfer represents a problem for public health. Comparison of human and animal ESBL-producing isolates is important in enhancing the knowledge of the potential routes of transfer of these bacteria and resistance genes in different ecosystems. In Tunisia, ESBL-producers were initially reported from food samples such as raw chicken meat (Jouini et al., 2007; Ben Slama et al., 2010). More recently, ESBLproducing $E$. coli were described in healthy food animals at farm level (Ben Sallem et al., 2012b, 2013; Mnif et al., 2012). In Tunisia, ESBL-producing bacteria were found in chickens and a dromedary, suggesting that poultry constitutes a major reservoir of ESBL genes. The dominant ESBL gene found was bla $a_{\mathrm{CTX}-\mathrm{M}-1}$, which was mainly detected with IncI1 replicons (Mnif et al., 2012). A recent study also demonstrated that the bla $a_{\mathrm{CTX}-\mathrm{M}-1}$ IncI1/ST3 plasmid was dominant in Tunisian chickens and pets (Grami et al., 2013). Finally, recent data showed that $7.3 \%$ of Tunisian healthy humans were fecal carriers of CTX-M-1-producing E. coli. This finding suggests that foodstuff of poultry origin may contribute to the transmission of the bla $a_{\mathrm{CTX}-\mathrm{M}-1}$ gene from animals to humans (Ben Sallem et al., 2012b).

The aim of this study was to characterize ESBL producing E. coli isolates recovered from feces of healthy chickens in Tunisia by investigating genes encoding ESBL, resistance to tetracycline, sulfonamides and fluoroquinolones as well as content of virulence genes, integrons, and genetic clonality using PFGE.

\section{Materials and Methods}

\section{Bacterial Strains}

Sixty-five fecal samples were collected from healthy chickens in 2013. Of these samples, 45 came from 58-week-old chickens in a farm located at Sidi Thabet in the North of Tunisia (Farm 1) and 20 from 7-week-old chickens in a farm located at Morneg region (Farm 2). These samples were cultivated on Mac-Conkey agar containing $2 \mathrm{mg} / \mathrm{L}$ of cefotaxime and incubated overnight at $37^{\circ} \mathrm{C}$. For each sample, one colony with typical E. coli trait was picked and re-isolated on Mac-Conkey agar and the phenotypic identification result was confirmed using Api20E (Bio-Mérieux, France).

\section{Antimicrobial Susceptibility Testing and ESBL Identification}

Antimicrobial susceptibility testing was carried out using the agar disk diffusion method on Mueller-Hinton agar plates in accordance with the Clinical and Laboratory Standards Institute guidelines (Clinical and Laboratory Standards Institute, 2012). The following antimicrobial agents were tested ( $\mu \mathrm{g} /$ disk): ampicillin (10), amoxicillin (25), amoxicillinclavulanic acid (20/10), ceftazidime (30), cefotaxime (30), gentamicin (10), kanamycin (30), streptomycin (10), amikacin (30), trimethoprim-sulfamethoxazol (1.25/23.75), tetracycline (30), nalidixic acid (30), ciprofloxacin (5), sulfonamides (200) and chloramphenicol (50). The Double-Disk Synergy Test (DDST) with cefotaxime or ceftazidime in the proximity to amoxicillin-clavulanic acid was used for the screening of ESBL (Clinical and Laboratory Standards Institute, 2012). E. coli ATCC25922 was used as ESBL negative and Klebsiella pneumoniae 700603 was used as ESBL positive reference strain.

\section{Resistance Genotype}

All primers used to characterize the resistance genotype are presented in Table 1. The presence of genes encoding TEM, SHV, CTX-M implicated in the beta-lactam resistance was analyzed by PCR (Sáenz, et al., 2004; Batchelor et al., 2005). Amplified DNA fragments were sequenced on both strands and the nucleotide and their deduced amino acid sequences were compared with those included in the Gen-Bank database as well as with those deposited at the website http://www. lahey.org/Studies/ in order to confirm the specific type of $\beta$ lactamase gene (Sáenz, et al., 2004; Batchelor et al., 2005). Genes encoding resistance to tetracycline (tet $A, \operatorname{tet} B$, and $\operatorname{tet} C)$, sulfonamide (sul1, sul2, and sul3), and quinolones ( $q n r A, q n r B$, and $q n r S$ ) were investigated by PCR as reported previously (Sáenz, et al., 2004; Wang et al., 2008; Rocha-Gracia et al., 2010). For positive isolates, PCR products of $q n r B$ and $q n r S$ were sequenced. The presence and characterization of integrons were studied by PCR of the class 1 and 2 integrase encoding genes as well as the $3^{\prime}$ conserved region (qacE $\Delta 1+$ sull genes) (Table 1) and by PCR and subsequent sequencing of the variables regions (VRs) of these integrons (Sáenz, et al., 2004). 
TABLE 1 | Primers of genes encoding resistance genes and integrons used in PCR of resistance genotype.

\begin{tabular}{|c|c|c|c|c|}
\hline Primer name & Sequence $\left(5^{\prime}-3^{\prime}\right)$ & Target gene or region & PCR products (bp) & References \\
\hline intl1-F & GGGTCAAGGATCTGGATITCG & intl1 & 483 & Sáenz, et al., 2004 \\
\hline intl1-R & ACATGCGTGTAAATCATCGTCG & & & \\
\hline Int-F & GGCATCCAAGCAGCAAG & Class 1 integron variable region & Variable & Sáenz, et al., 2004 \\
\hline Int-R & AAGCAGACTTGACCTGA & & & \\
\hline intl2-F & CACGGATATGCGACAAAAAGGT & intl2 & 788 & Sáenz, et al., 2004 \\
\hline intl2-R & GTAGCAAACGAGTGACGAAATG & & & \\
\hline Hep-F & CGGGATCCCGGACGGCATGCACGATTTGTA & Class 2 integron variable region & Variable & Sáenz, et al., 2004 \\
\hline Hep-R & GATGCCATCGCAAGTACGAG & & & \\
\hline Qac-F & GGCTGGCTाTTCTGTTATCG & qacE $\Delta 1$-sul1 region & 1125 & Sáenz, et al., 2004 \\
\hline SUL1-R & GCGAGGGTTCCGAGAAGGTG & & & \\
\hline SUL1-F & TGGTGACGGTGTTCGGCATTC & sul1 & 789 & Sáenz, et al., 2004 \\
\hline SUL1-R & GCGAGGGTITCCGAGAAGGTG & & & \\
\hline SUL2-F & CGGCATCGTCAACATAACC & sul2 & 722 & Sáenz, et al., 2004 \\
\hline SUL2-R & GTGTGCGGATGAAGTCAG & & & \\
\hline SUL3-F & CATTCTAGAAAACAGTCGTAGTTCG & sul 3 & 990 & Sáenz, et al., 2004 \\
\hline SUL3-R & CATCTGCAGCTAACCTAGGGCTITGGA & & & \\
\hline TetA-F & GTAATTCTGAGCACTGTCGC & tetA & 937 & Sáenz, et al., 2004 \\
\hline TetA-R & CTGCCTGGACAACATTGCTT & & & \\
\hline TetB-F & CTCAGTATTCCAAGCCTITG & tetB & 416 & Sáenz, et al., 2004 \\
\hline TetB-R & CTAAGCACTTGTCTCCTGTT & & & \\
\hline TetC-F & TCTAACAATGCGCTCATCGT & tetC & 570 & Sáenz, et al., 2004 \\
\hline TetC-R & GGTTGAAGGCTCTCAAGGGC & & & \\
\hline aac $\left(6^{\prime}\right)-1 b-F$ & TTGCGATGCTCTATGAGTGGCTA & $a a c\left(6^{\prime}\right)-I b$ & 482 & Rocha-Gracia et al., 2010 \\
\hline aac(6')-lb-R & CTCGAATGCCTGGCGTGTIT & & & \\
\hline QepA-F & GGACATCTACGGCTTCTTCG & qepA & 671 & Rocha-Gracia et al., 2010 \\
\hline QepA-R & CAACTGCTTGAGCCCGTAG & & & \\
\hline QnrA-F & GGGTATGGATATTATTGATAAA & qnrA & 580 & Rocha-Gracia et al., 2010 \\
\hline QnrA-R & CTAATCCGGCAGCACTATTA & & & \\
\hline QnrBnew-F & GATCGTGAAAGCCAGAAAGG & qnrB & 468 & Wang et al., 2008 \\
\hline QnrBnew-R & ACGATGCCTGGTAGTTGTCC & & & \\
\hline QnrS-F & AGTGATCTCACCTTCACCGC & qnrS & 550 & Rocha-Gracia et al., 2010 \\
\hline QnrS-R & CAGGCTGCAATITTGATACC & & & \\
\hline TEM-F & ATTCTTGAAGACGAAAGGGC & blaTEM & 1150 & Sáenz, et al., 2004 \\
\hline TEM-R & ACGCTCAGTGGAACGAAAAC & & & \\
\hline SHV-F & CACTCAAGGATGTATTGTG & blaSHV & 885 & Sáenz, et al., 2004 \\
\hline SHV-R & TTAGCGTTGCCAGTGCTCG & & & \\
\hline CTXM-Univ-F & CGATGTGCAGTACCAGTAA & blaCTXM & 585 & Batchelor et al., 2005 \\
\hline CTXM-Univ-R & TTAGTGACCAGAATCAGCGG & & & \\
\hline
\end{tabular}

\section{Virulence Genotyping}

The presence of 30 virulence genes (fimA, TartT, iutA, MaIX, Ibe, FyuA, BmaE, papGalleleIII, papC, colV, cdtB, papG alleleI, nfaE, SfaS, iha, iss, ire, ehxA, sxt1, sxt2, eltA, fasA, estII, aggC, esat1, $c d t$, ipah, $h l y, c n f 1$, and $b f p$ ) was determined by using PCR in all ESBL-positive E. coli strains (Chapman et al., 2006; Wu et al., 2007).

\section{Clonal and Phylogenetic Analysis of E. coli Isolates}

Chromosomal DNA was prepared as previously described using the restriction enzyme XbaI (Amersham Life Sciences, Uppsala, Sweden) (Kaufmann, 1998). DNA fragments were separated by electrophoresis in $1.2 \%$ agarose gels (pulsed-field agarose certified; Bio-Rad, Hemel Hempstead, United Kingdom) and $0.5 \mathrm{X}$ Tris-borate-EDTA buffer using a contour-clamped homogeneous electric field (CHEF-DRIII system; Bio-Rad) under the following electrophoresis conditions: $12^{\circ} \mathrm{C}$ at $6 \mathrm{~V} / \mathrm{cm}$ for $27 \mathrm{~h}$ with pulse times ranging from 10 to 40 s. Clonal relationships were established following Tenover criteria (Tenover et al., 1995). E. coli Isolates were allotted to phylogenetic groups $\mathrm{A}, \mathrm{B} 1, \mathrm{~B} 2$, or $\mathrm{D}$, using a triplex $\mathrm{PCR}$ assay targeting the $c h u A, y j a A$ genes and the DNA fragment TSPE4.C2 (Clermont et al., 2000). Strains were sub-grouped according to Escobar-Paramo et al. (2006): subgroup A0: chuA-, yjaA-, and TspE4.C2-; subgroup A1: chuA-, yjaA+, and TspE4.C2-; 
group B1: chuA-, yjaA+/-, and TspE4.C2+; subgroup $\mathrm{B} 2_{2}$ : chuA+, yjaA+, and TspE4.C2-; subgroup $\mathrm{B} 2{ }_{3}: \operatorname{chuA}+, y j a A+$, and TspE4.C2+; subgroup D1: chuA+, yjaA-, and TspE4.C2-; subgroup D2: chuA+, yjaA, and TspE4.C2+. Appropriate positive and negative controls were included in the assay.

\section{Results}

\section{Occurrence of ESBL-producing E. coli Isolates and Antibiotic Susceptibility}

Eleven (24\%) and 6 (30\%) ESBL-producing E. coli isolates were detected in the 45 and 20 fecal samples collected in farm 1 and in farm 2, respectively. In addition to ESBL production, isolates in farm 1 have the same profile of resistance to nalidixic acid, norfloxacine (intermediate), trimethoprimsulfamethoxazole, sulfonamides, streptomycin and tetracycline. But, they remained susceptible to imipenem, gentamicin, tobramycin and chloramphenicol. With the exception of one strain that was co-resistant to tetracycline, isolates, from farm 2, were susceptible to all non beta-lactam antibiotics (Table 2).

\section{Gene Coding for the Production of ESBL}

PCR and sequencing showed that all strains, except one, harbored the bla $a_{\mathrm{CTX}-\mathrm{M}-1}$ genes. One strain co-harbored bla $a_{\mathrm{TEM}-1}$ gene. The $b l a_{\text {SHV }}$ gene was not detected.

\section{Occurrence of Class 1 and 2 Integrons}

In farm 1, class 1 and 2 integrons were found in one and ten isolates, respectively. In farm 2 , class 1 integron was found in only one isolate, while class 2 was not detected. Amplification of the
VRs of class 2 integrons showed identical DNA fragments with an approximate size of $2000 \mathrm{bp}$. All these VRs contained a unique gene cassette arrangement, being $d f r A 1$ - sat2-aadA1, encoding resistance for trimethoprim, streptothricin and streptomycin, respectively. In one isolate, the VR of class 1 integron was amplified and yielded a DNA fragment of ca. $250 \mathrm{bp}$, whereas no amplification was observed in the second int1-positive isolate.

\section{Determination of Phylogroups and Virulence Factors}

In farm 1, all isolates were found to belong to phylogroup A (subgroup $\mathrm{A} 0$ ); however, different phylogroups were detected in farm 2 ( $\mathrm{A} 1, \mathrm{~B} 2_{2}$, and $\mathrm{B} 2_{3}$, each in one isolate, and $\mathrm{D}_{2}$, in 3 isolates). The virulence genes iut(A), fimH, and traT were detected in 3 , 7 , and 3 isolates, respectively. The other genes were not detected in our collection. Two types of gene combination were detected: $i u t A+f i m H+t r a T$ (in 3 isolates); $i u t A+f i m H$ (in one isolate).

\section{Genes Encoding Tetracycline-, Sulphonamide, and Fluroquinolones Resistance}

Amongst the 12 tetracycline-resistant isolates, eleven and one carried tet $A$ and tet $B$, respectively. Sulfonamides resistance was encoded by sul1, sul2 and sul3 genes in 3,17 and 5 isolates, respectively. Gene qnrB1 was detected in 9 isolates, one of them co-harbored qnrS1 gene.

\section{PFGE Typing}

All isolates from farm 1 were clonally related, while isolates of the farm 2 were genetically unrelated (Figure 1).

TABLE 2 | Phenotypic and molecular characteristics of the 17 ESBL-producing E. coli isolates.

\begin{tabular}{|c|c|c|c|c|c|c|c|c|c|c|}
\hline E. coli strain & Resistance profil* & $\begin{array}{c}\text { Phylogenetic } \\
\text { group }\end{array}$ & $\beta$-Lactamase (s) & $\ln t^{\star \star}$ & $\mathrm{VR}^{\star \star}(\mathrm{bp})$ & tet & sul & PMQR $^{\star \star}$ & $\begin{array}{l}\text { Virulence } \\
\text { factors }\end{array}$ & $\begin{array}{c}\text { PFGE } \\
\text { type }\end{array}$ \\
\hline Ec139 & NA, Norl, Sxt, S, Tet & Ao & CTX-M-1 & 2 & 2000 & A & sul 2 & qnrB1 & iut $A$ & A \\
\hline Ec149 & NA, Norl', Sxt, S, Tet & Ao & CTX-M-1 & 2 & 2000 & A & sul 1-2 & - & iut $A$ & A \\
\hline Ec174 & NA, Norl', Sxt, S, Tet & Ao & CTX-M-1 & 2 & 2000 & A & sul 2 & - & iut $A$ & A \\
\hline Ec143 & NA, Norl, Sxt, S, Tet & Ao & CTX-M-1 & 2 & 2000 & A & sul 2 & qnrB1 & iut $A$ & A \\
\hline Ec147 & NA, Norl, Sxt, S, Tet & Ao & CTX-M1 & 2 & 2000 & A & sul 2 & - & iut $A$ & A \\
\hline Ec154 & NA, Norl, Sxt, S, Tet & Ao & CTX-M1 & 2 & 2000 & $A$ & sul 2 & qnrB1 & iut $A$ & A \\
\hline Ec146 & NA, Norl, Sxt, S, Tet & Ao & CTX-M1 & 2 & 2000 & A & sul 1-2 & - & iut $A$ & A \\
\hline Ec172 & NA, Norl, Sxt, S, Tet & Ao & CTX-M-1+ TEM-1 & 1 & 250 & A & sul 2-3 & qnrB1 & iut $A$, traT, fimH & A \\
\hline Ec156 & NA, Norl, Sxt, S, Tet & Ao & CTX-M-1 & 2 & 2000 & A & sul 2 & qnrB1, qnrS1 & - & A \\
\hline Ec151 & NA, Nor', Sxt, S, Tet & Ao & CTX-M-1 & 2 & 2000 & $A$ & sul 2 & qnrB1 & iut $A$ & A \\
\hline Ec173 & NA, Norl, Sxt, S, Tet & Ao & CTX-M-1 & 2 & 2000 & $A$ & sul 2 & qnrB1 & iut $A$ & A \\
\hline Ec67 & - & $\mathrm{A} 1$ & CTX-M-1 & 1 & - & - & sul 1-2 & - & $\mathrm{fimH}$ & $\mathrm{B}$ \\
\hline Ec68 & TET & $B 2_{2}$ & - & - & - & $\mathrm{B}$ & sul 2-3 & - & iut $A$, traT, fimH & C \\
\hline Ec69 & - & $\mathrm{D}_{2}$ & CTX-M-1 & - & - & - & sul 2 & qnrB1 & iut $A$, traT, fimH & $\mathrm{D}$ \\
\hline Ec71 & - & $\mathrm{B} 2_{3}$ & CTX-M-1 & - & - & - & sul 2-3 & qnrB1 & iut $A$, fimH & $E$ \\
\hline Ec 72 & - & $\mathrm{D}_{2}$ & CTX-M-1 & - & - & - & sul 2-3 & - & $\mathrm{fimH}$ & $\mathrm{F}$ \\
\hline Ec 76 & - & $D_{2}$ & CTX-M-1 & - & - & - & sul 2-3 & - & $\mathrm{fimH}$ & G \\
\hline
\end{tabular}

${ }^{*}$ Resistance to other antibiotic in addition to ESBL production, NA, nalidixic acid; Nor, Norfloxacine; Sxt, trimethoprim-sulfamethozole; S, streptomycin; Tet, tetracycline.

${ }^{\star *} /$ Int, integron class; VR, variable region; PMQR, Plasmid Mediated Quinolone Resistance. 


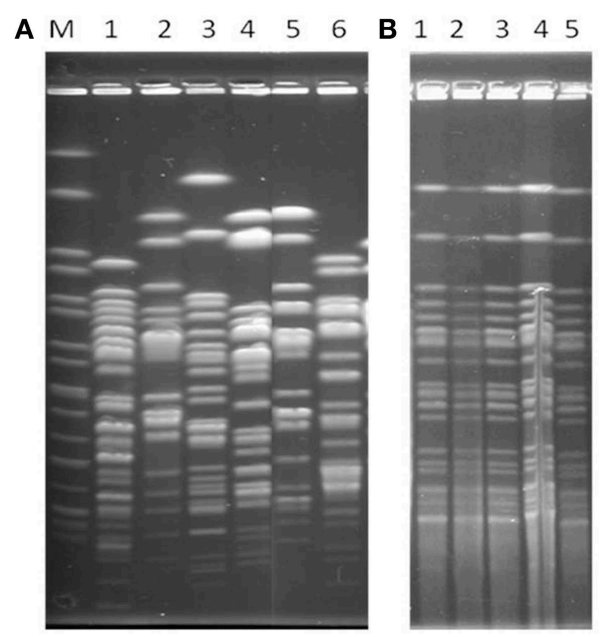

FIGURE 1 | Xbal-PFGE profiles of representative $E$. coli isolates. (A, Unrelated isolates) Lanes M, Xbal-digested DNA of Salmonella enterica serovar Braenderup H9812, used as size standard; Lanes 1-6, Ec 67, Ec68, Ec69, Ec71, Ec72; (B, Clonal isolates) Lanes 1 to5, EC139, EC149, Ec 174, Ec143, Ec147, respectively.

\section{Discussion}

We collected 65 samples of feces from 45 reproductive 58 -weeksold chickens in a public farm in the region of Sidi Thabet (30 Km Nord-West of Tunis, Tunisia) (Farm1) and 20 samples of 7-weeks-old breeder chickens in the region of Morneg (Farm 2). Seventeen samples $(26.1 \%)$ contained cefotaxime-resistant isolates, $11(24 \%)$ and $6(30 \%)$ positives samples were observed in farms 1 and 2, respectively. The frequency of cefotaximeresistant isolates is similar to those reported by other authors worldwide (2\%; 31.7\%) (Dierikx et al., 2013; Randall et al., 2014), but lower than those found by other studies in Tunisia ( $42 \%$ and 45, 5\%) (Ben Sallem et al., 2012b; Mnif et al., 2012). In our study, all isolates from farm 1 exhibited the same resistance profile to nalidixic acid, trimethoprim-sulfamethoxazole, sulfonamides, streptomycin, tetracycline and norfloxacine (intermediately resistant). These resistance markers are often reported in previous Tunisian studies (Ben Slama et al., 2010; Mnif et al., 2012). All isolates were susceptible to imipenem, gentamicin, kanamycin and chloramphenicol. Indeed, low rates of resistance to these antibiotics have been reported worldwide (Grami et al., 2013). However, the 6 isolates from farm 2, except one that was co-resistant to tetracycline, were susceptible to all antibiotics tested. Worldwide, the CTX-M group has been emerged as the predominant determinant encoding ESBL production in human and animal Enterobacteriaceae, especially E. coli (Girlich et al., 2007; Coque et al., 2008; Nicolas-Chanoine et al., 2008; Dahmen et al., 2012, 2013). The bla $a_{\text {CTX-M-1 gene was amplified in } 16}$ out of 17 isolates; in addition, one isolate co-harbored the bla $a_{\mathrm{TEM}-1}$ gene. This result is in agreement with those of other Tunisian findings (Jouini et al., 2007, 2009; Ben Slama et al., 2010; Ben Sallem et al., 2012b, 2013; Mnif et al., 2012). The high rate occurrence of $E$. coli harboring $b l_{\mathrm{CTX}-\mathrm{M}-1}$ in poultry and other food products of animal origin can contribute to the transmission of this gene or these strains to humans. Indeed, it was recently demonstrated that E. coli containing CTX-M-1 was identified in 7.3\% of healthy Tunisians (Ben Sallem et al., 2012a). Identical or closely related isolates from humans and animals have been previously reported in Netherlands, suggesting a likely transmission of ESBL-E. coli isolates from poultry to human, most probably via the food chain (Overdevest et al., 2011). More recently, Chinese data showed a high occurrence of CTX-M-14 in isolates from animals where this enzyme is very widespread in human isolates (Zheng et al., 2012). In the EC68 strain, no bla gene was detected. This strain could harbor a gene not investigated in our study. Further investigation must be undertaken. Antibiotic resistance, especially the multiresistance, has been mainly linked to the dissemination of linked genes encoding resistance inserted in mobile genetic elements, mainly integrons. Integron of class 1 was found in two isolates while integron of class 2 in ten isolates. Our results are not in agreement with other findings, which showed the dominance of integron of class 1 in animal-derived E. coli or in animal products as well as human isolates (Machado et al., 2005; Soufi et al., 2009, 2011; Ben Slama et al., 2010; Cergole-Novella et al., 2010). Two hypotheses could explain our finding: firstly, the real absence of class 1 integrons in the integron-free isolates, as reported by other authors (Jouini et al., 2007; Ben Sallem et al., 2012b). Secondly, the presence of insertion sequences, such as IS26, truncating the intI and thus, leading to inhibition of PCR amplification. In the case of truncated intI gene by IS26, the use of other primers was proposed (Marchant et al., 2013). Owing to a number of financial limitations, we could not realize these PCRs actually. The then int2-positive isolates presented an identical gene cassette array in their VRs: dfrA-sat2-aadA1, being frequent in other studies (Soufi et al., 2009, 2011). The integrase Int2 is not functional and thus unable to integrate new gene cassettes into the variable region, other than those already present (Partridge et al., 2009). The variable region of the class 2 integron mainly carries $d f r A 1$ (encoding trimethoprim resistance), sat 1 (encoding streptothricin resistance) and aadA1 (encoding streptomycin/spectinomycin resistance) (Partridge et al., 2009; Soufi et al., 2009, 2011). The size of the VR of class 1 integron in EC172 was approximately $250 \mathrm{bp}$, a fragment that cannot correspond to any gene cassette of the known ones (Ravi et al., 2014). The VR of class 1 integron in EC67 was not amplified; this might suggest an empty VR or mismatches of used primers.

Tetracycline resistance was encoded by tet $A$ and tet $B$ genes in 11 and one tetracycline-resistant isolates, respectively. This finding was also reported by other studies (Koo and Woo, 2011; Xibiao et al., 2011), while the tetC gene is rarely reported (Skoèková et al., 2013). The sul1, sul2 and sul3 genes were detected in 3, 17, and 5 isolates, respectively, not only amongst sulfonamid resistant isolates, but also in the six-sulfonamide susceptible isolates. In other reports, sull is most frequently reported followed by sul2 gene while sul3 gene is generally less so (Sköld, 2000; Perreten and Boerlin, 2003; Hammerum et al., 2006; Trobos et al., 2008). Resistance toward quinolone and fluoroquinolones is mainly due to target mutations in quinolone 
resistance determining region (QRDR) of DNA gyrase ( $g y r A$ and gyrB) and topoisomerases IV (parC and parE) (Hawkey, 2003). However, Plasmid Mediate Quinolone Resistance (PMQR) genes such as $q n r A, q n r B, q n r C, q n r D, q n r S$, qepA, and $a a c\left(6^{\prime}\right) I b-c r$ have been increasingly reported in bacterial pathogens since 2000 (Strahilevitz et al., 2009). In our study, among 11 isolates resistant to nalidixic acid and intermediately susceptible sensibility to norfloxacine, seven isolates carried qnrB1 gene and one also co-heberged qnrS1 gene. These two genes were often reported by other authors worldwide (Ben Sallem et al., 2013, 2014; Ferjani et al., 2014) in E. coli producers of CTX-M from human and animal origin. In our study, we did not consider $q e p A$ and aac $\left(6^{\prime}\right)-I b-c r$ genes, while other authors reported their presence in E. coli from animal origin (Ma et al., 2009; Xie et al., 2014). The $q n r$ gene types have no big effect on the increase of minimal inhibitory concentration (MIC) of fluoroquinolones (ciprofloxacine and norfloxacine) and were generally not detected by disk diffusion method. Indeed, the resistance toward quinolones in 7 amongst the 11 nalidixic acid resistant isolates could be explained by these qnr genes but it could also certainly explained by the presence of chromosomal mutations in QRDR of GyrA and/or ParC (Abbassi et al., 2010). The quinolone-susceptible isolate containing qnrB1 gene confirmed the low level expression of this resistance (in term of increase of MIC).

Concerning the distribution of pathogenic E. coli strains according to phylogroups, it is well-known that pathogenic strains producing extra-intestinal infections (ExPEC) belong mainly to the $\mathrm{B} 2$ group and less to the $\mathrm{D}$ group. They are responsible for meningitidis, abscess, peritonitis, septicemia and urinary tract infections (Le Gall et al., 2007; Nandanwar et al., 2014); while, groups A and B1 E. coli strains are considered nonvirulent commensal strains (Ewers et al., 2007). All the strains of farm 1 were found to belong to the phylogroup A (sub-type $\mathrm{A} 0$ ), while, the strains of farm 2 to phylogroups $\mathrm{A}$ ( $\mathrm{A} 1,1$ isolate), $\mathrm{D}$ (D2, 3 isolates) and $\mathrm{B} 2\left(\mathrm{~B} 22_{2}, 1\right.$ isolate; $\mathrm{B} 2_{3}, 1$ isolate). In the literature, the majority of animal $E$. coli isolates producing ESBL belonged to phylogroup A and B1 (Mnif et al., 2012; Huber et al., 2013) contrary to human isolates, which mainly belonged to B2 phylogroup. The low number of virulence genes detected was in relation with the appurtenance of our isolates (12/17) to the phylogroup A. Strains of phylogroups B2 and D were

\section{References}

Abbassi, M. S., Ruiz, E., Saenz, Y., Mechergui, A., Ben Hassen, A., and Torres, C. (2010). Genetic background of quinolones resistance in CTX-M-15-producing Klebsiella pneumonia and Escherichia coli strains in Tunisia. J. Chemother. 22, 66-67. doi: 10.1179/joc.2010.22.1.66

Alexander, T. W., Inglis, G. D., Yanke, L. J., Topp, E., Read, R. R., Reuter, T., et al. (2010). Farm-to-fork characterization of Escherichia coli associated with feedlot cattle with a known history of antimicrobial use. Int. J. Food Microbiol. 137, 40-48. doi: 10.1016/j.ijfoodmicro.2009.11.008

Batchelor, M., Hopkins, K., Threlfall, E. J., Clifton-Hadley, F. A., Stallwood, A. D., Davies, R. H., et al. (2005). bla $a_{C T X-M}$ genes in clinical Salmonella isolates recovered from humans in England and Wales from 1992 to 2003. Antimicrob. Agents Chemother. 49, 1319-1322. doi: 10.1128/AAC.49.4.1319-1322.2005 somewhat distinguished from strains of phylogroup A by the occurrence of the fimbrial fim $H$ gene and the serum resistanceassociated outer membrane (traT). The low number of genes detected could be explained by fitness notion or the competitively of strains. Indeed, these avian intestinal E. coli isolates were under selective presser by antibiotics. This selective pressure enhances the expansion and maintenance of antibiotic-resistant strains rather than virulent ones.

PFGE showed that the 11 isolates of the farm 1 were indistinguishable, while isolates of farm 2 were unrelated. The cloanlity of these isolates would evoke a strong power of dissemination of clonal isolates in this poultry breeding. The difference in genetic contents in isolates of farm2 (sul genes, $q n r$ genes and virulence genes) might be due to independent acquisition of genes carried by plasmids or integrons.

\section{Conclusion}

Despite the limited samples analyzed in this study, that might not reflect the real epidemiological situation of avian ESBLproducing E. coli in these two farms, our study showed two typical epidemiologic characteristics of ESBL-producing bacteria. Firstly, clonal isolates are disseminated within the same farm. Secondly, "singleton" isolates occur with limited ability of spread, evoking the potential horizontal transfer of ESBL genes between different E. coli populations. Plasmids or integrons might be implicated in the mobilization of bla $a_{\mathrm{CTX}-\mathrm{M}-1}$ genes among avian isolates. Further studies should be performed in the future to track the evolution of ESBL types and their frequencies in different ecosystems.

\section{Author Contributions}

HK, MA, RM, SH, NC, and IB: Conceiving and designing the study, collecting and interpreting the data, and writing the article. SS, RS, IJ, and SF: interpreting the data, revising the article.

\section{Acknowledgments}

This work was supported by the Tunisian Ministry of Higher Education and Scientific Research. 
Ben Sallem, R., Ben Slama, K., Rojo-Bezares, B., Porres-Osante, N., Jouini, A., Klibi, N., et al. (2014). IncI1 plasmids carrying $b l a_{C T X-M-1}$ or $b l a_{C M Y-2}$ genes in Escherichia coli from healthy humans and animals in Tunisia. Microb. Drug. Resist. 20, 495-500. doi:10.1089/mdr.2013.0224

Ben Slama, K., Jouini, A., Bem Sallem, R., Somalo, S., Saenz, Y., Estepa, V., et al. (2010). Prevalence of broad-spectrum cephalosporin-resistant Escherichia coli isolates in food samples in Tunisia, and characterization of integrons and antimicrobial resistance mechanisms implicated. Int. J. Microbiol. Food. 137, 281-286. doi: 10.1016/j.ijfoodmicro.2009.12.003

Blanc, V., Mesa, R., Saco, M., Lavilla, S., Prats, G., Miró, E., et al. (2006). ESBL- and plasmidic class C beta-lactamase-producing E. coli strains isolated from poultry, pig and rabbit farms. Vet. Microbiol. 118, 299-304. doi: 10.1016/j.vetmic.2006.08.002

Brinas, L., Moreno, M. A., Teshager, T., Saenz, Y., Porrero, M. C., Dominguez, L., et al. (2005). Monitoring and characterization of extended-spectrum beta-lactamases in Escherichia coli strains from healthy and sick animals in Spain in 2003. Antimicrob. Agents Chemother. 49, 1262-1264. doi: 10.1128/AAC.49.3.1262-1264.2005

Canton, R., Gonzales-Alba, J. M., and Galan, R. C. (2012). CTX-M- enzymes: origin and diffusion. Front. Microbiol. 3:110. doi: 10.3389/fmicb.2012.00110

Cergole-Novella, M. C., Guth, B. E., Castanheira, M., Carmo, M. S., and Pignatari, A. C. (2010). First description of bla $a_{C T X-M-14^{-}}$and $b l a_{C T X-M-15}$-producing Escherichia coli isolates in Brazil. Microb. Drug Resist. 16, 177-184. doi: 10.1089/mdr.2010.0008

Chapman, T. A., Wu, X. Y., Barchia, I., Bettelheim, K. A., Driesen, S., Trott, D., et al. (2006). Comparison of virulence gene profiles of Escherichia coli strains isolated from healthy and diarrheic swine. Appl. Environ. Microbiol. 72, 4782-4795. doi: 10.1128/AEM.02885-05

Clermont, O., Bonacorsi, S., and Bingen, E. (2000). Rapid and simple determination of the Escherichia coli phylogenetic group. Appl. Environ. Microbiol. 66, 4555-4558. doi: 10.1128/AEM.66.10.45554558.2000

Clinical and Laboratory Standards Institute. (2012). Performance Standards for Antimicrobial Susceptibility Testing; Twenty-second Informational Supplement. Clinical and Laboratory Standards Institute Document M100-S22. Wayne, PA: Clinical and Laboratory Standards Institute.

Coque, T. M., Novais, A., Carattoli, A., Poirel, L., Pitout, J., Peixe, L., et al. (2008). Dissemination of clonally related Escherichia coli strains expressing extendedspectrum beta-lactamase CTX-M-15. Emerg. Infect. Dis. 14, 195-200. doi: 10.3201/eid1402.070350

Cortés, P., Blanc, V., Mora, A., Dahbi, G., Blanco, J. E., Blanco, M., et al. (2010). Isolation and characterization of potentially pathogenic antimicrobial-resistant Escherichia coli strains from chicken and pig farms in Spain. Appl. Environ. Microbiol. 76, 2799-2805. doi: 10.1128/AEM.02421-09

Dahmen, S., Haenni, M., and Madec, J. Y. (2012). IncI1/ ST3 plasmids contribute to the dissemination of the bla $a_{C T X-M-1}$ gene in Escherichia coli from several animal species in France. J. Antimicrob. Chemother. 67, 3011-3012. doi: $10.1093 / \mathrm{jac} / \mathrm{dks} 308$

Dahmen, S., Metayer, V., Gay, E., Madec, J. Y., and Haenni, M. (2013). Characterization of extended-spectrum beta-lactamase (ESBL)-carrying plasmids and clones of Enterobacteriaceae causing cattle mastitis in France. Vet. Microbiol. 162, 793-799. doi: 10.1016/j.vetmic.2012.10.015

Dierikx, C. M., vander Goot, J. A., Smith, H. E., Kant, A., and Mevius, D. J. (2013). Presence of ESBL/AmpC-producing Escherichia coli in the broiler production pyramid: a descriptive study. PLOS ONE 8:e79005. doi: 10.1371/journal.pone.0079005

Dutil, L. R., Irwin, R., Finley, L. K., Ng, B., Avery, P., Boerlin, A. M., et al. (2010). Ceftiofur resistance in Salmonella enterica serovar Heidelberg from chicken meat and humans, Canada. Emerg. Infect. Dis. 16, 48-54. doi: 10.3201/eid1601.090729

Eckert, C., Gautier, V., Saladin-Allard, M., Hidri, N., Verdet, C., Ould-Hocine, Z., et al. (2004). Dissemination of CTX-M-type $\beta$-lactamases among clinical isolates of Enterobacteriaceae in Paris, France. Antimicrob. Agents Chemother. 48, 1249-1255. doi: 10.1128/AAC.48.4.1249-1255.2004

Escobar-Paramo, P., Le Menac'h, A., Le Gall, T., Amorin, C., Gouriou, S., Picard, B., et al. (2006). Identification of forces shaping the commensal Escherichia coli genetic structure by comparing animal and human isolates. Environ. Microbiol. 8, 1975-1984. doi: 10.1111/j.1462-2920.2006.01077.x
Ewers, C., Li, G., Wilking, H., Kiessling, S., Alt, K., Antáo, E. M., et al. (2007). Avian pathogenic, uropathogenic, and newborn meningitis-causing Escherichia coli: how closely related are they? Int. J. Med. Microbiol. 297, 163-176. doi: 10.1016/j.ijmm.2007.01.003

Ferjani, S., Saidani, M., Amine, F. S., and Boutiba-Ben Boubaker, I. (2014). Prevalence and characterization of plasmid-mediated quinolone resistance genes in extended-spectrum $\beta$-lactamase-producing Enterobacteriaceae in a Tunisian hospital. Microb. Drug. Resist. 21, 158-166. doi: 10.1089/mdr.2014.0053

Girlich, D., Poirel, L., Carattoli, A., Kempf, I., Lartigue, M. F., Bertini, A., et al. (2007). Extended-spectrum $\beta$-lactamase CTX-M-1 in Escherichia coli isolates from healthy poultry in France. Appl. Environ. Microbiol. 73, 4681-4685. doi: 10.1128/AEM.02491-06

Grami, R., Mansour, W., Dahmen, S., Mehri, W., Haenni, M., Aouni, M., et al. (2013). The bla $a_{C T X-M-1}$ IncI1/ST3 plasmids dominate in chickens and pets in Tunisia. J. Antimicrob. Chemother. 68, 2950-2952. doi: 10.1093/jac/dkt258

Hammerum, A. M, Sandvang, D., Andersen, S. R., Seyfarth, A. M., Porsbo, L. J., Frimodt-Møller, N., et al. (2006). Detection of sull, sul2 and sul3 in sulphonamide resistant Escherichia coli isolates obtained from healthy humans, pork and pigs in Denmark. Int. J. Food Microbiol. 106, 235-237. doi: 10.1016/j.ijfoodmicro.2005.06.023

Hawkey, P. M. (2003). Mechanisms of quinolone action and microbial response. J. Antimicrob. Chemother. 51, 29-35. doi: 10.1093/jac/dkg207

Huber, H., Zweilfel, C., Wittenbrink, M. M., and Stephan, R. (2013). ESBLProducing uropathogenic Escherichia coli isolated from dogs and cats in Switzerland. Vet. Microbiol. 162, 992-996. doi: 10.1016/j.vetmic.2012. 10.029

Jouini, A., Ben Slama, K., Saenz, Y., Klibi, N., Costa, D., Vinué, L., et al. (2009). Detection of multiple-antimicrobial resistance and characterization of the implicated genes in Escherichia coli isolates from foods of animal origin in Tunis. Food Prot. 72, 76-82.

Jouini, A., Vinué, L., Ben Slama, K., Saenz, Y., Klibi, N., Hammami, S., et al. (2007). Characterization of CTX-M and SHV extended-spectrum beta-lactamases and associated resistance genes in Escherichia coli strains of food samples in Tunisia. J. Antimicrob. Chemother. 60, 1137-1141. doi: 10.1093/jac/dkm316

Kaufmann, M. E. (1998). "Pulsed-field gel electrophoresis," in Methods in Molecular Medicine, Vol. 15, Molecular Bacteriology: Protocols and Clinical Applications, eds N. Woodford and A. P. Johnson (Totowa, NJ: Humana Press, Inc.), $17-31$.

Koo, H. J., and Woo, G. J. (2011). Distribution and transferability of tetracycline resistance determinants in Escherichia coli isolated from meat and meat products. Int. J. Food Microbiol. 145, 407-413. doi: 10.1016/j.ijfoodmicro.2011.01.003

Le Gall, T., Clermont, O., Gouriou, S., Picard, B., Nassif, X., Denamur, E., et al. (2007). Extraintestinal virulence is a coincidental by-product of commensalism in B2 phylogenetic group Escherichia coli strains. Mol. Biol. Evol. 24, 2373-2384. doi: 10.1093/molbev/msm172

Li, X. Z., Mehrotra, M., Ghimire, S., and Adewoye, L. (2007). Beta-lactam resistance and beta-lactamases in bacteria of animal origin. Vet. Microb. 121, 873-880. doi: 10.1016/j.vetmic.2007.01.015

Livermore, D. M., Canton, R., Gniadkowski, M., Nordmann, P., Rossolini, G. M., Arlet, G., et al. (2007). CTX-M: changing the face of ESBLs in Europe J. Antimicrob. Chemother. 59, 165-174. doi: 10.1093/jac/dkl483

Ma, J., Zeng, Z., Chen, Z., Xu, X., Wang, X., Deng, Y., et al. (2009). High prevalence of plasmid-mediated quinolone resistance in determinants qnr, aac(6)-Ib-cr, and qepA among ceftiofur-resistant Enterobacteraceae isolates from companion and food-producing animals. Antimicrob. Agents Chemother. 53, 519-524. doi: 10.1128/AAC.00886-08

Machado, E., Canton, R., Baquero, F., Galan, J. C, Rollan, A., Peixe, L., et al. (2005). Integron content of extended spectrum- $\beta$-lactamase-producing Escherichia coli strains over 12 years in a single hospital in Madrid, Spain. Antmicrob. Agents Chemother. 49, 1823-1829. doi: 10.1128/AAC.49.5.1823-1829.2005

Marchant, M., Vinué, L., Torres, C., and Moreno, M. A. (2013). Change of integrons over time in Escherichia coli isolates recovered from healthy pigs and chickens. Vet. Microbiol. 163, 124-132. doi: 10.1016/j.vetmic.2012. 12.011

Mnif, B., Ktari, S., Rhimi, F. M., and Hammami, A. (2012). Extensive dissemination of CTX-M-1-and CMY-2-producing Escherichia coli in poultry 
farms in Tunisia. Lett. Appl. Microbiol. 55, 407-413. doi: 10.1111/j.1472765X.2012.03309.X

Nandanwar, N., Janssen, T., Kühl, M., Ahmed, N., Ewers, C., and Wieler, L. H. (2014). Extraintestinal pathogenic Escherichia coli (ExPEC) of human and avian origin belonging to sequence type complex 95 (STC95) portray indistinguishable virulence features. Int. J. Med. Microbiol. 304, 835-842. doi: 10.1016/j.ijmm.2014.06.009

Naseer, U., and Sundsfjord, A. (2011). The CTX-M conundrum: dissemination of plasmids and Escherichia coli clones. Microb. Drug. Resist. 17, 83-97. doi: $10.1089 / \mathrm{mdr} .2010 .0132$

Nicolas-Chanoine, M. H., Blanco, J., Leflon-Guibout, V., Demarty, R. M., Alonso, P., Caniça, M. M., et al. (2008). Intercontinental emergence of Escherichia coli clones O25:H4-ST131 producing CTX-M-15. J. Antimicrob. Chemother. 61, 273-281. doi: 10.1093/jac/dkm464

Overdevest, I., Willemsen, I., Rijnsburger, M., Eustace, A., Xu, L., Hawkey, P., et al. (2011). Extended-spectrum $\beta$-lactamase genes of Escherichia coli in chicken meat and humans, The Netherlands. Emerg. Infect. Dis. 17, 1216-1222. doi: 10.3201/eid1707.110209

Partridge, S. R., Tsafnat, G., Coiera, E., and Iredell, J. R. (2009). Gene cassettes and cassette arrays in mobile resistance integrons. FEMS Microbiol. Rev. 3, 757-784. doi: 10.1111/j.1574-6976.2009.00175.x

Perreten, V., and Boerlin, P. (2003). A new sulfonamide resistance gene (sul3) in Escherichia coli is widespread in the pig population of Switzerland. Antimicrob. Agents. Chemother. 47, 1169-1172. doi: 10.1128/AAC.47.3.11691172.2003

Pitout, J. D., and Laupland, K. B. (2008). Extended-spectrum $\beta$-lactamaseproducing Enterobacteriaceae: an emerging public-health concern. Lancet Infect. Dis. 8, 159-166. doi: 10.1016/S1473-3099(08)70041-0

Randall, L., Heinrich, K., Horton, R., Brunton, L., Sharman, M., Bailey-Horne, V., et al. (2014). Detection of antibiotic residues and association of cefquinome residues with the occurrence of extended-spectrum $\beta$-lactamase (ESBL) producing bacteria in waste milk samples from dairy farms in England and Wales in 2011. Res. Vet. Sci. 96, 15-24. doi: 10.1016/j.rvsc.2013.10.009

Ravi, A., Avershina, E., Ludvigsen, J., L'Abée-Lund, T. M., and Rudi, K. (2014). Integrons in the intestinal microbiota as reservoirs for transmission of antibiotic resistance genes. Pathogens 3, 238-248. doi: 10.3390/pathogens3020238

Rocha-Gracia, R., Ruiz, E., Romero-Romero, S., Lozano-Zarain, P., Somalo, S., Palacios-Hernández, J. M., et al. (2010). Detection of plasmid-borne quinolone resistance determinant qepA1 in a CTX-M-15 producing Escherichia coli from Mexico. J Antimicrob. Chemother. 65, 169-171. doi: 10.1093/jac/dkp418

Ryu, S. H., Lee, J. H., Park, S. H., Song, M. O., Park, S. H., Jung, H. W., et al. (2012). Antimicrobial resistance profiles among Escherichia coli strains isolated from commercial and cooked foods. Int. J. Food Microbiol. 159, 263-266. doi: 10.1016/j.ijfoodmicro.2012.09.001

Sáenz, Y., Briñas, L., Dominguez, E., Ruiz, J., Zarazaga, M., Vila, J., et al. (2004). Mechanisms of resistance in multiple-antibiotic-resistant Escherichia coli strains of human, animal, and food origins. Antimicrob. Agents Chemother. 48, 3996-4001. doi: 10.1128/AAC.48.10.3996-4001.2004

Skoèková, A., Karpíšková, R., Koláèková, I. and Cupáková, Š. (2013). Characteristics of Escherichia coli from raw vegetables at a retail market in the Czech Republic. Int. J. Food Microbiol. 167, 196-201. doi: 10.1016/j.ijfoodmicro.2013.09.011

Sköld, O. (2000). Sulfonamide resistance: mechanisms and trends. Drug. Resist. Updat. 3, 155-160. doi: 10.1054/drup.2000.0146

Smet, A., Martel, A., Persoons, D., Dewulf, J., Heyndrickx, M., Catry, B., et al. (2008). Diversity of extended-spectrum b-lactamases and class C betalactamases among cloacal Escherichia coli isolates in Belgian broiler farms. Antimicrob. Agents Chemother. 52, 1238-1243. doi: 10.1128/AAC.01285-07
Soufi, L., Abbassi, M. S., Saenz, A., Vinué, L., Somalo, S., Zarazaga, M., et al. (2009). Prevalence and diversity of integrons and associated resistance genes in Escherichia coli isolates from Poultry meat in Tunisia. Foodborne Patho. Dis. 6, 1067-1073. doi: 10.1089/fpd.2009.0284

Soufi, L., Sáenz, Y., Vinué, L., Abbassi, M. S., Ruiz, E., Zarazaga, M., et al. (2011). Escherichia coli of poultry food origin as reservoir of sulphonamide resistance genes and integrons. Int. J. Food Microbiol. 144, 497-502. doi: 10.1016/j.ijfoodmicro.2010.11.008

Strahilevitz, J., Jacoby, G. A., Hooper, D. C., and Robicsek, A. (2009). Plasmidmediated quinolone resistance: a multifaceted threat. Clin. Microbiol. Rev. 22, 664-689. doi: 10.1128/CMR.00016-09

Tenover, F. C., Arbeit, R. D., Goering, R. V., Mickelsen, P. A., Murray, B. E., Persing, D. H., et al. (1995). Interpreting chromosomal DNA restriction patterns produced by pulsed-field gel electrophoresis: criteria for bacterial strain typing. J. Clin. Microbiol. 33, 2233-2239.

Trobos, M., Jakobsen, L., Olsen, K. E., Frimodt-Møller, N., Hammerum, A. M., Pedersen, K., et al. (2008). Prevalence of sulphonamide resistance and class 1 integron genes in Escherichia coli isolates obtained from broilers, broiler meat, healthy humans and urinary infections in Denmark. Int. J. Antimicrob. Agents 32, 367-369. doi: 10.1016/j.ijantimicag.2008. 04.021

Vinué, L., Saenz, Y., Martinez, S., Somalo, S., Moreno, M. A., Torres, C., et al. (2009). Prevalence and diversity of extended spectrum betalactamases in faecal Escherichia coli isolates from healthy humans in Spain. Clin. Microbiol. Infect. 15, 954-957. doi: 10.1111/j.1469-0691.2009. 02803.x

Wang, A., Yang, Y., Lu, Q., Wang, Y., Chen, Y, Deng, L, et al. (2008). Presence of qnr gene in Escherichia coli and Klebsiella pneumoniae resistant to ciprofloxacin isolated from pediatric patients in China. BMC Infect. Dis. 22, 8-68. doi: 10.1186/1471-2334-8-68

Wu, X. Y., Chapman, T., Trott, D. J., Bettelheim, K., Do, T. N., Driesen, S., et al. (2007). Comparative analysis of virulence genes, genetic diversity and phylogeny between commensal and enterotoxigenic Escherichia coli from weaned pigs. Appl. Environ. Microbiol. 73, 83-91. doi: 10.1128/AEM. 00990-06

Xibiao, T., Chen, T., Xuan, Z., Zhanqin, Z., Xin, X., Bin, W., et al. (2011). Antimicrobial resistances of extraintestinal pathogenic Escherichia coli isolates from swine in China. Microbial. Pathogenesis. 50, 207-212. doi: 10.1016/j.micpath.2011.01.004

Xie, R., Huo, S., Li, Y., Chen, L., Zhang, F., and Wu, X. (2014). Molecular epidemiological survey on quinolone resistance genotype and phenotype of Escherichia coli in septicemic broilers in Hebei, China. Poult. Sci. 93, 335-339. doi: $10.3382 /$ ps.2013-03522

Zheng, H., Zeng, Z., Chen, S., Liu, Y., Yao, Q., Deng, Y., et al. (2012). Prevalence and characterization of CTX-M $\beta$-lactamases amongst Escherichia coli isolates from healthy food animals in China. Int. J. Antimicrobiol. Agents 39, 305-310. doi: 10.1016/j.ijantimicag.2011.12.001

Conflict of Interest Statement: The authors declare that the research was conducted in the absence of any commercial or financial relationships that could be construed as a potential conflict of interest.

Copyright $\odot 2015$ Kilani, Abbassi, Ferjani, Mansouri, Sghaier, Ben Salem, Jaouani, Douja, Brahim, Hammami, Ben Chehida and Boubaker. This is an open-access article distributed under the terms of the Creative Commons Attribution License (CC $B Y)$. The use, distribution or reproduction in other forums is permitted, provided the original author(s) or licensor are credited and that the original publication in this journal is cited, in accordance with accepted academic practice. No use, distribution or reproduction is permitted which does not comply with these terms. 